\title{
Develop the AI Literacy of Infants by Deeply Integrated English Learning and Robot Education
}

\author{
Zhongyu Zhang \\ Modern Educational technology institute of Qujing Normal University, Qujing, Yunnan , China 655000
}

\begin{abstract}
In this paper, a new learning model which integrate the English Learning and Robot Education for infants was proposed. According to this model, a textbook of using robot to teach English was designed. A corresponding course which matched with the textbook was developed. An experiment of using this course was done in a training institution. The result illustrate that this model is apparently effective for the kindergarten school students to learn English and robot.
\end{abstract}

Keywords-integrate; English learning; robot education; language skill, intelligent; information literacy; science and technology literacy

\section{INTRODUCTION}

Artificial Intelligent (AI) is becoming more and more important whether in research field or industry. Chinese government had given out a plan which named about the new generation AI industry development plan, in which the AI industry had been put the most important place [1]. According to this plan, The GDP will reach 1,000 billion Yan in directly AI industry and 10,000 billion Yan in indirectly related industry in 2030. With the rapid progress of this plan, the AI personnel training is much necessary. As Dengxiaoping, a great Chinese president, had put it that the computer education must begin from the babies [2]. An Excellent AI personnel must also begin to be trained from a baby. As our viewpoint, An Excellent AI personnel must have not only higher science and technology literacy but also better foreign language skills.

However, in many primary schools or kindergartens, no matter the English learning or the AI education is very poor. Robot is the best media for children to learning AI knowledge. In a survey about the English learning and robot education to the Kindergartens in Qujing. Almost all the public kindergarten have not English and robot course. More than 90 percent private kindergartens have not English and robot courses. Early childhood is the key time to learn a language. The adage that "it is never too early to begin reading to infants and toddlers" appears throughout both the professional and popular literatures [3]. The information, science and technology literacy should be developed in Children's early childhood. So perhaps integrating the English learning and robot education will be a very good method to develop the AI literacy of early children. In this paper, a new learning model which integrate the English Learning and Robot Education for the infants was proposed. According to this model, an experiment of deeply integrated the English learning and robot education was done in a training institution. The result illustrate that the effects of learning English and robot is very good. So we can conclusion that the deeply integration model is apparently effective for the kindergarten school students to learn English and robot.

\section{WHY IS IT IMPORTANT FOR INFANTS TO LEARN ENGLISH AND ROBOT}

With the development of AI industry. The requirement of AI professionals will grow more and more rapidly. The problem of lack of AI professionals will exist for a long time. During the past a few years, the high, elementary and secondary school had spent more time in raising the student test scores and less time in developing the AI literacy of them. The social training organization didn't also focus on the AI field but more and more on the physical exercise and art. The college and university have planned to found the AI-related majors or subjects. Where will the students come from? The students which enter into these AIrelated majors will not be the high quality source if they are not good at electronics, information and programming. Most of the advanced country pay high attention to develop the AI literacy of the high, elementary and secondary school students, or even kindergarten infants. It is related for students to develop their literacy during the time they learn from kindergarten to the college or university. So developing the AI literacy of infants is also very important. Robot, as a kind of hardware product of AI industry, is the most suitable tool to develop the AI literacy of infants. Jigsaw robot is a very good product. According to the related research, the benefits of learning robots are as follows [4]:

(1) For the left brain, it is beneficial to:

- Instill math and science interest

- Improve memory power

- Increase concentration

- Critical thinking skills

- Logical and analytical skills

- Communication skills

(2) For the right brain, it is beneficial to:

- Reduce study stress

- Spatial reasoning

- Imaginative skills

- Creative thinking skills

- Problem solving skills

- Innovation skills 
In our training practice, we also found most of the kindergarten infants or the primary school students can't master English as a second language. As we think, English is very important for students to be taught to become the leaders in the future AI times. Early childhood is the key time to develop the language skills of children.

Here we try to explore the path of integrated the English learning and robot education for the infants.

\section{HOW TO INTEGRATE THE ENGLISH LEARNING AND ROBOT EDUCATION}

How to integrate the English learning and robot education. The aims of English g and robot learning for the infants are what the educator should think firstly. Generally speaking, the aims of English learning often include the listening, speaking, reading and writing. But to infants, listening and speaking is probably more suitable and reading and writing is probably not. As for the robot education, building up, operating and program thinking excising is the main point for infants.

According to the describing above, a model for developing the AI literacy of infants by integrating English learning and robot education together was proposed. A textbook was designed. A corresponding course match with this text book can be developed. In this course, the basic teaching and learning equipment include the Lego jigsaw robot and Zhongming Weier robot suit products. Weier is a jigsaw robot with an intelligent pen to control the robot. When the infants use the intelligent pen to point the special chart in the textbook, the robot can display the corresponding action. This equipment can be use as the programming excising.

Teachers can design a lot of activities to teach English and robot by using these equipment. The robot learning focus on the building up, operating and controlling and programming. The jigsaws are the most suitable for the English teaching and learning. For example, the teaching of colors, shapes, size, letters, numbers and so on can be done by using of Lego jigsaws. During the process of building up the robots, some simple operating actions can be express by English. For example, Put the two squares together. Put the triangle on the top of the robot. etc,. Zhongming Weier robot also provide a program thinking excising textbook. Infants can be taught and master the basic program ideas and logics. The benefits of this model is that infants can master not only the English skills but also robot professional knowledge. The most important feature is that the infants can be immersed in the English and robot learning activities all the long time.

\section{AN EXPERIMENT OF INTEGRATING ENGLISH LEARNING AND ROBOT EDUCATION FOR INFANTS}

In order to verify the effects of the above model, an experiment of using this mode to teach infants to learn English and robot knowledge was held in a training institution. The experiment method is the pretest and posttest of a single group. The treatments is ten infants whose ages are between $4-6$ years old. There are five boys and five girls in this 10 infants. They didn't all have learnt English before. The learning content include concepts, operating sentences and programing thinking.

Task 1: English concept learning activity.
Content of English concept learning activity is the nine kinds of colors in our life. They are red, blue, yellow, green, orange, purple, brown, black and white.

Task 2: English sentences learning activity.

The content of English sentences learning activity included the seven English sentences of operating the Weier jigsaw robot:

- Programming starts.

- Go forward 1 second.

- Take backwards 2seconds

- Turn left 3seconds.

- Turn right 4 seconds.

- Stop.

- Programming is over.

The aim of this learning activity includes:

(1) The pronouncing of all the words in these sentences.

(2) The meaning of all the words in these sentences.

(3) The fluently reading of all these sentences.

(4) The translating of all these sentences.

In task 1, teacher guided the boys and girls when she built up the same robot as what the infants did. Boys and girls looked the teacher as their partner. So they felt very naturally and didn't feel to be learning English. They naturally followed the teacher saying English words. Parents can also play the role of teacher. It is also effective to do the shared parent-infant book reading on early language acquisition [5].

The result of task 1 illustrate the time to master the nine kinds of colors is less than in the traditional classroom. When they play the Weier robot.

In task 2, teacher guided the boys and girls operating the intelligent pen to control the Zhongming Weier robot. At the same time, teacher teach the boys and girls to say out the English sentences corresponding to the operating. Infants looked saying English as a part of the game or the story [6]. So they can easily speak out all the sentences.

The result of task 1 and 2 also illustrated that all the boys and girls were interested in the learning process. In the traditional teaching process, the time of infants concentrate on a learning activity is less than 10 minutes. But in this experiment, the time of infants concentrating on a learning activity is more than half an hour. Infants seemed to be no tired when they build up and operating the robot.

\section{CONCLUSIONS AND FUTURE WORK}

In this paper, a new learning model which integrate the English Learning and Robot Education for infants was proposed. According to this model, a textbook by using of robots to teach English was designed. A corresponding course which matched with this textbook was developed. In order to verify the effects of this model, an experiment of using this course was done in a training institution. The result illustrate that this model is 
apparently effective for the kindergarten school students to learn English and robot. Infants can easily complete the learning task and master the English skills. In addition to the better learning effectiveness, the nonintellectual factors of infants, such as interest, attention, and willpower, are also developed to some extent.

Certainly, the above model pointed out only the basic path to integrate the English learning and robot education. The experiment used also only a basic English learning materials. How to design more and more learning materials? Whether this model is suitable to the students of other ages? These are our future research work.

\section{REFERENCES}

[1] The state concil issued the informs of the development plan about new generation of AI industry. State issued [2017]No. 35. http://www.gov.cn/zhengce/content/2017-07/20/content_5211996.htm

[2] Dengxiaopinginspected Shanghai: Computer education must begin from the babies. http://www.chinanews.com/gn/2014/08-22/6522779.shtml

[3] Dunst, C. J., Simkus, A., \& Hamby, D. W. Relationship between age of onset and frequency of reading to infants and toddlers and later language and literacy development. CELLreviews, 5(3), 1-10. Available at http://www.earlyliteracylearning.org/cellreviews/cellreviews_v5_n3.pdf

[4] Benefits of Robotics Learning. http://www.robots2u.com/benefits/ benefits.php

[5] Karrass, J., \& Braungart-Ricker, J. M. (2005). Effects of shared parentinfant book reading on early language acquisition. Journal of Applied Developmental Psychology, 26, 133-148.

[6] Zeece, P. D., \& Churchill, S. L. (2001). First stories: Emergent literacy in infants and toddlers. Early Childhood Education Journal, 29, 101-104. doi:10.1023/A:1012572812166 